\title{
Correction to: Acute cardiovascular events in patients with community acquired pneumonia: results from the observational prospective FADOI-ICECAP study
}

Filippo Pieralli ${ }^{1}$, Vieri Vannucchi ${ }^{2}$, Carlo Nozzoli ${ }^{1}$, Giuseppe Augello ${ }^{3}$, Francesco Dentali ${ }^{4}$, Giulia De Marzi ${ }^{1}$, Generoso Uomo ${ }^{5}$, Filippo Risaliti ${ }^{6}$, Laura Morbidoni ${ }^{7}$, Antonino Mazzone ${ }^{8}$, Claudio Santini ${ }^{9}$, Daniela Tirotta ${ }^{10}$, Francesco Corradi ${ }^{11}$, Riccardo Gerloni ${ }^{12}$, Paola Gnerre ${ }^{13}$, Gualberto Gussoni ${ }^{14}$, Antonella Valerio ${ }^{14^{*}}$, Mauro Campanini ${ }^{15}$, Dario Manfellotto ${ }^{16}$, Andrea Fontanella ${ }^{17}$ and for the FADOI-ICECAP Study Group

Correction to: BMC Infect Dis (2021) 21:116

https://doi.org/10.1186/s12879-021-05781-w

After publication of the original article [1], an error was identified in one of the ICECAP Study Group member's name, listed in the Appendix section.

The incorrect name is: MG Pierfranceschi

The correct name should be: M Giorgi-Pierfranceschi

The original article has been corrected.

\begin{abstract}
Author details
'Intermediate Care Unit, Azienda Ospedaliero-Universitaria Careggi, Florence, Italy. ${ }^{2}$ Internal Medicine, Hospital "Santa Maria Nuova" Florence, Florence, Italy. IInternal Medicine, P.O. "Barone Lombardo", Canicattì, AG, Italy. "Internal Medicine, Hospital of Luino, ASST-Sette Laghi, and University of Insubria, Varese, Italy. ${ }^{5}$ Medical Department, Internal Medicine, Hospital

"Cardarelli",Pieralli et al. BMC Infectious Diseases (2021) 21:116 Page 11 of 12, Naples, Italy. Internal Medicine, Hospital of Prato, Prato, Italy. ${ }^{7}$ Internal Medicine, Hospital "Civile" of Senigallia, Ancona, Italy. ${ }^{8}$ Medical Department, Internal Medicine, Hospital "Civile" of Legnano, Milan, Italy. 'Medical Department, Internal Medicine, Hospital "Vannini", Rome, Italy. ${ }^{10}$ Internal Medicine, Hospital of Cattolica, Rimini, Italy. ${ }^{11}$ Medical Department, Internal Medicine 2, Azienda Ospedaliero-Universitaria Careggi, Florence, Italy. ${ }^{12}$ Internal Medicine, "Ospedali Riuniti di Trieste", Trieste, Italy. ${ }^{13}$ Internal Medicine, "San Paolo" Hospital, Savona, Italy. ${ }^{14}$ Research Department, FADOI Foundation, Piazzale Cadorna, 15, 20123 Milan, Italy. ${ }^{15}$ Department of Internal Medicine, Hospital "Maggiore della Carità", Novara, Italy. ${ }^{16}$ Department of Internal Medicine, Ospedale Fatebenefratelli-AFaR, Isola Tiberina, Rome, Italy.
\end{abstract}

${ }^{17}$ Medical Department, Hospital "Buon Consiglio-Fatebenefratelli", Naples, Italy.

Published online: 19 February 2021

\section{Reference}

1. Pieralli F, et al. Acute cardiovascular events in patients with community acquired pneumonia: results from the observational prospective FADOIICECAP study. BMC Infect Dis. 2021;21:116. https://doi.org/10.1186/s12879021-05781-w.

The original article can be found online at https://doi.org/10.1186/s12879021-05781-w.

* Correspondence: antonella.valerio@fadoi.org

${ }^{14}$ Research Department, FADOI Foundation, Piazzale Cadorna, 15, 20123 Milan, Italy

Full list of author information is available at the end of the article

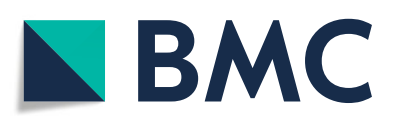

(c) The Author(s). 2021 Open Access This article is licensed under a Creative Commons Attribution 4.0 International License, which permits use, sharing, adaptation, distribution and reproduction in any medium or format, as long as you give appropriate credit to the original author(s) and the source, provide a link to the Creative Commons licence, and indicate if changes were made. The images or other third party material in this article are included in the article's Creative Commons licence, unless indicated otherwise in a credit line to the material. If material is not included in the article's Creative Commons licence and your intended use is not permitted by statutory regulation or exceeds the permitted use, you will need to obtain permission directly from the copyright holder. To view a copy of this licence, visit http://creativecommons.org/licenses/by/4.0/ The Creative Commons Public Domain Dedication waiver (http://creativecommons.org/publicdomain/zero/1.0/) applies to the data made available in this article, unless otherwise stated in a credit line to the data. 